\title{
Vigor de sementes e competição intra-específica em soja
}

\author{
Seeds vigor and intra-specific compettion in soybean
}

\author{
Eliane Maria Kolchinski ${ }^{1}$ Luis Osmar Braga Schuch ${ }^{2}$ Silmar Teichert Peske ${ }^{2}$
}

\section{RESUMO}

\begin{abstract}
O experimento teve como objetivo avaliar o efeito de combinações da distribuição das sementes de soja de alto e baixo vigor ao longo da linha de semeadura, sobre o comportamento individual das plantas resultantes e o desempenho geral das comunidades. Utilizou-se o cultivar de soja BRS 154. Foram avaliadas seis combinações de vigor das sementes na linha de semeadura. As plantas provenientes das sementes de alto vigor apresentaram maior índice de área foliar, produção de matéria seca e rendimento de sementes, em relação às plantas provenientes das sementes de baixo vigor. As plantas originadas das sementes de alto vigor não exerceram efeito de dominância sobre as plantas provenientes das sementes de baixo vigor, adjacentes na linha de semeadura. O aumento na proporção das sementes de alto vigor no estabelecimento das comunidades de plantas, proporcionou acréscimos lineares no índice de área foliar, na produção de matéria seca e no rendimento de sementes. A população formada somente por plantas oriundas das sementes de alto vigor, apresentou rendimento $30 \%$ superior à população constituída somente por plantas originadas das sementes de baixo vigor.

Palavras-chave: Glycine $\max ($ L.) Merrill, qualidade fisiológica, matéria seca, índice de área foliar, rendimento.
\end{abstract}

\section{ABSTRACT}

The objective of this research was to evaluate the effect of high and low vigor soybean seeds combinations distribution in the planting row on individual plants and different communities performance. The cultivar BRS 154 was used. Six seed vigor combinations were used. Plants from high vigor seeds had higher leaf area, dry matter accumulation and seed yield than plants from low vigor seeds. Plants from high vigor seeds do not have dominance effect on plants from low vigor adjacent in the row. The increases in proportion of high vigor seeds in the establishment of the plants communities provided linears increments in leaf area index, dry matter production and seeds yield. The population established with all plants from of high vigor seeds out yield in more than $30 \%$ the population established only with plants from low vigor seeds.

Key words: Glycine $\max ($ L.) Merrill, physiological quality, dry matter, leaf area index, yield.

\section{INTRODUÇÃO}

Ao longo dos anos, vem buscando-se incrementar a produção da soja no Brasil, por meio do aumento na área plantada e/ou rendimento por área. Neste contexto, é fundamental o uso de sementes de alta qualidade na implantação das lavouras. Sementes com baixo vigor podem provocar reduções na velocidade e na emergência total, no tamanho inicial, na produção de matéria seca, na área foliar e nas taxas de crescimento das plantas (KHAH et al. 1989; SCHUCH, 1999; SCHUCH et al. 2000; MACHADO, 2002; HÖFS, 2003) podendo afetar o estabelecimento da cultura, o seu desempenho ao longo do ciclo e a produtividade final. EDJE \& BURRIS (1971) constaram que as sementes de soja de baixo vigor emergiram mais lentamente e produziram plantas com menor tamanho inicial. Nesse sentido, PINTHUS \& KIMEL (1979) observaram que as plântulas de soja que emergiram

${ }^{1}$ Universidade Estadual do Rio Grande do Sul (UERGS). Rua Alegrete 821, Bairro São José, 95960-000, Encantado, RS, Brasil. Email: eliane-kolchinski@uergs.edu.br. Autor para correspondência.

${ }^{2}$ Departamento de Fitotecnia, Faculdade de Agronomia "Eliseu Maciel”, Universidade Federal de Pelotas, Pelotas, RS, Brasil. 
rapidamente, apresentaram as primeiras folhas trifolioladas maiores em relação às plântulas de menor vigor, resultando em maior taxa de acúmulo de matéria seca ao longo do período de crescimento.

Um lote apresenta variações na qualidade fisiológica entre as sementes. Lotes com menor vigor, em função da maior variação entre as sementes, apresentam maior desuniformidade e menor velocidade na emergência. SCHUCH et al. (1999) verificaram que a redução no nível do vigor das sementes aumentou o tempo médio necessário para a protrusão das radículas, bem como reduziu o número médio de radículas emitidas por dia. A maior velocidade na emergência e a produção de plântulas com maior tamanho pode proporcionar às plantas provenientes das sementes vigorosas uma vantagem inicial no aproveitamento de água, luz e nutrientes. Dentro do lote, estas plântulas ao emergirem mais rapidamente, iniciam o processo fotossintético mais cedo, favorecendo o crescimento da parte aérea e do sistema radicular. Embora, a diferença inicial seja pequena entre as plântulas, esta pode influenciar a competição intraespecífica, como observado por BLACK (1958). O autor constatou que as plântulas com maior área foliar e altura, em estágios posteriores do desenvolvimento, predominaram sobre as plantas que se desenvolveram menos no estágio de plântulas. Desta forma, esperase que as plantas oriundas das sementes mais vigorosas, em função da maior área foliar e taxas de crescimento (SCHUCH, 1999; SCHUCH et al., 2000; MACHADO, 2002), sejam mais eficientes na competição por luz. Assim, associando plantas originárias de sementes com diferentes níveis de vigor, provavelmente, as plantas com maior crescimento aéreo afetarão a intensidade e a composição da luz incidente sobre as plantas com menor crescimento na comunidade vegetal e, por conseqüência, possivelmente refletirá no desenvolvimento e produção individual dessas plantas.

Diversos trabalhos têm demonstrado diferenças competitivas entre plantas dentro de comunidades, em que as plantas mais desenvolvidas apresentam vantagem na competição intra-específica. Esses trabalhos utilizaram a metodologia de variação na data de semeadura, em covas adjacentes na linha de semeadura, para produzir a desuniformidade na emergência. EGLI (1993) constatou que as plantas de soja emergidas mais cedo sempre tiveram vantagem competitiva sobre as plantas emergidas posteriormente, em posições alternadas na mesma fileira e tal vantagem refletiu em maior rendimento de grãos por planta. Nesse sentido, NAFZIGER et al. (1991) constataram que o aumento na proporção de plantas de emergência antecipada na comunidade, reduziu progressivamente o rendimento das plantas que emergiram mais tarde. Em milho, MEROTTO JÚNIOR et al. (1999) observaram que as plantas que emergiram tardiamente foram dominadas, e ocorreu uma compensação por parte das plantas que emergiram primeiro. No entanto, a compensação, não foi suficiente para proporcionar rendimento de grãos semelhante ao de uma comunidade com emergência uniforme.

A competição entre plantas tem sido assunto de pesquisa há muitos anos. No entanto, são escassos os trabalhos que estudam os efeitos devidos aos diferentes níveis de vigor entre as sementes dentro de um lote, sobre a uniformidade na emergência, o tamanho inicial das plântulas, a taxa de crescimento da cultura, a posterior competição intra-específica, o rendimento de sementes das plantas individuais dentro das comunidades, e o comportamento geral das comunidades.

Desta forma, o presente trabalho teve como objetivo avaliar o efeito de diferentes combinações da distribuição das sementes de alto e baixo vigor, ao longo da linha da semeadura sobre o comportamento individual das plantas resultantes e o desempenho geral das comunidades, incluindo a produção de sementes de soja.

\section{MATERIAL E MÉTODOS}

O experimento foi conduzido na Área Experimental da Faculdade de Agronomia "Eliseu Maciel” da Universidade Federal de Pelotas, no município de Capão do Leão - RS. A análise do solo realizada antes da instalação do experimento indicou: teor de argila: $170 \mathrm{~g} \mathrm{~kg}^{-1}$; Índice SMP: 6,1; MO: 24,5g $\mathrm{dm}^{-3}$; P:30,3mg dm${ }^{-3}$ e $\mathrm{K}: 46 \mathrm{mg} \mathrm{dm}^{-3}$. O solo foi preparado com uma aração e duas gradagens e aplicados $24 \mathrm{~kg} \mathrm{ha}^{-1}$ de superfosfato triplo e $120 \mathrm{~kg} \mathrm{ha}^{-1}$ de cloreto de potássio.

Os tratamentos constaram de seis combinações de distribuição das sementes de alto e baixo vigor ao longo da linha de semeadura. Utilizouse o cultivar de soja (Glycine $\boldsymbol{m a x}$ (L.) Merrill), BRS 154. O delineamento experimental utilizado foi o de blocos ao acaso com quatro repetições.

As combinações de distribuição das sementes de alto e baixo vigor ao longo da linha de semeadura foram as seguintes: 1 . Todas as sementes de alto vigor (1A:1A); 2. Duas sementes de alto vigor seguidas por uma semente de baixo vigor (2A:1B); 3 . Uma semente de alto vigor seguida por uma semente de baixo vigor (1A:1B); 4. Uma semente de alto vigor 
seguida por duas sementes de baixo vigor (1A: 2B); 5 . Uma semente de alto vigor seguida por três sementes de baixo vigor (1A:3B); 6 . Todas as sementes de baixo vigor (1B:1B). Cada parcela constitui-se de uma combinação de vigor de sementes.

As combinações corresponderam às seguintes proporções das plantas provenientes das sementes de alto vigor na comunidade: 1,0 (A:A); 0,67 (2A:1B); 0,50 (1A:1B); 0,33 (1A:2B); 0,25 (1A:3B). Na combinação 1A:3B, foram avaliadas separadamente, as plantas provenientes das sementes de baixo vigor localizadas imediatamente ao lado das plantas oriundas das sementes de alto vigor, na linha da semeadura, e as localizadas na posição intermediária (entre duas plantas de baixo vigor), e para fins de avaliação, receberam a denominação de B1 e B2, respectivamente.

$\mathrm{O}$ alto vigor das sementes foi obtido pela utilização de um lote com 95\% de germinação e 94\% de emergência. A determinação da emergência foi realizada em canteiros utilizando solo como substrato. As sementes de baixo vigor foram obtidas a partir daquele mesmo lote, mediante a aplicação do envelhecimento acelerado utilizando o método do gerbox (MARCOS FILHO, 1999) a $41^{\circ} \mathrm{C}$ e $100 \%$ de UR por um período de 72 horas. Após o tratamento, as sementes foram analisadas e apresentavam 75\% de germinação e 70\% de emergência (determinada em canteiros).

A semeadura foi realizada em 10/12/2001, utilizando duas semeadoras manuais (saraquá), uma contendo as sementes de alto vigor e a outra, as sementes de baixo vigor. A semeadura foi realizada de acordo com as combinações de vigor, especificadas anteriormente. Por exemplo, na combinação $1 \mathrm{~A}: 1 \mathrm{~B}$, semeou-se uma cova com aproximadamente três sementes de alto vigor e a seguinte, com aproximadamente quatro sementes de baixo vigor, e assim sucessivamente ao longo da linha de semeadura. Utilizaram-se espaçamentos entre covas na linha de $5,5 \mathrm{~cm}$ e entre linhas de $45 \mathrm{~cm}$. A profundidade de semeadura foi uniformizada em $2,5 \mathrm{~cm}$, utilizando um delimitador de profundidade nas semeadoras.

Em função da variação na qualidade fisiológica entre as sementes dentro do lote e para obter as plântulas mais representativas do comportamento médio, semearam-se de três a quatro sementes por cova. Posteriormente, realizou-se o desbaste deixando uma planta por cova. O desbaste baseou-se em testes preliminares, em que a maior parte das plântulas do lote com alto vigor emergiu no quarto e quinto dia após a semeadura, e do lote com baixo vigor, no sexto e sétimo dia após a semeadura. $\mathrm{O}$ desbaste ajustou a população em 40 plantas $\mathrm{m}^{-2}$.
No momento da semeadura, as covas contendo as sementes de alto vigor, foram marcadas com estacas de madeira. Tal procedimento permitiu a identificação das plantas de alto vigor dentro das comunidades e a realização das determinações experimentais durante o ciclo da cultura.

Aos 30 dias após a emergência (DAE) e no estádio R2 (pleno florescimento), foram coletadas 20 plantas em cada nível do vigor e posição da semeadura, para a determinação do índice de área foliar (IAF) e a produção de matéria seca. A área foliar das plantas foi determinada utilizando um determinador fotoelétrico e a produção de matéria seca através do método de estufa a $55^{\circ} \mathrm{C}$ por 72 horas (NEDEL, 1990).

Na maturação, foram colhidas 20 plantas provenientes de cada nível do vigor e posição da semeadura, dentro da área útil de cada parcela, para a determinação da produção de matéria seca, número de vagens por planta, número de sementes por vagem, peso de mil sementes e rendimento de sementes. $\mathrm{O}$ rendimento de sementes foi determinado, transformando os dados para kg.ha ${ }^{-1}$ e corrigindo para 13\% de umidade.

Os valores obtidos em cada nível do vigor e posição da semeadura foram avaliados individualmente, e posteriormente somados, para determinação do comportamento geral das diferentes comunidades.

Os dados experimentais foram submetidos à análise da variância. O comportamento individual das plantas foi avaliado por comparações de médias, através do teste de Duncan ao nível de 5\% de significância, enquanto o desempenho das comunidades, por regressões polinomiais.

\section{RESULTADOS E DISCUSSÃO}

Comportamento individual das plantas

Os resultados apresentados na figura 1 mostram que as plantas provenientes das sementes de alto vigor apresentaram maior índice de área foliar (IAF) em relação às plantas provenientes das sementes de baixo vigor, aos 30 dias após a emergência (DAE) e na floração em todas as combinações. Aos 30 DAE, as plantas originadas das sementes de baixo vigor apresentaram valor médio de 1,28 , enquanto que as oriundas das sementes de alto vigor, valor em torno de 2,0, indicando um aumento no IAF de aproximadamente $56 \%$. Na floração, o aumento no IAF, chegou a $67 \%$.

Constata-se que o efeito do vigor das sementes sobre a produção de matéria seca foi similar ao observado no IAF. As plantas provenientes das sementes de alto vigor apresentaram maiores 


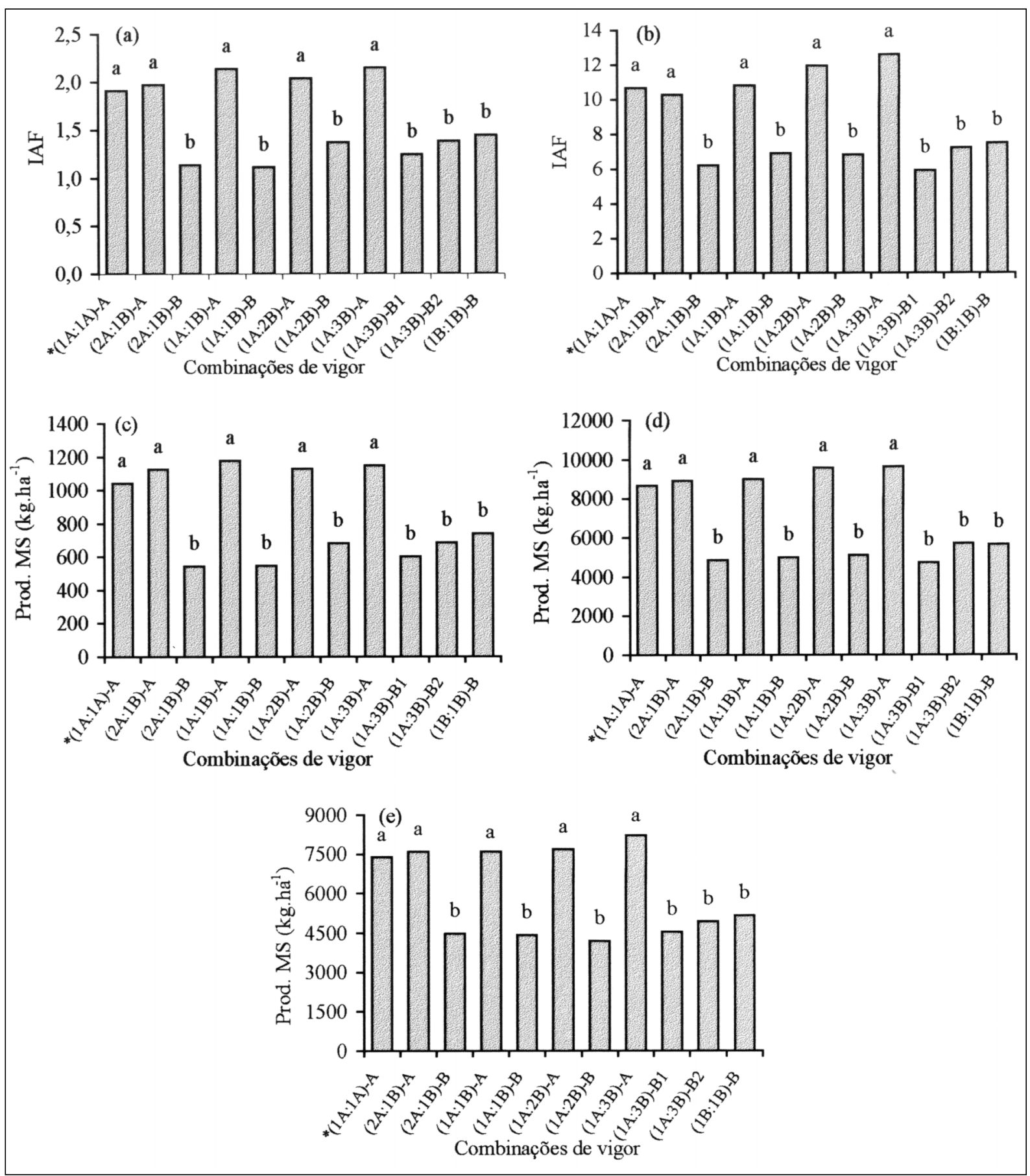

Figura 1 - Índice de área foliar (IAF) aos 30 dias após a emergência (a) e na R2 (b) e produção de matéria seca (MS) 30 dias após a emergência (c), na R2 (d) e R7 (e) das plantas individuais dentro das comunidades de plantas de soja, em função de combinações do vigor das sementes. Capão do Leão-RS, 2001/2002.

*(1A:1A)-A; (2A:1B)-A; (1A:1B)-A; (1A:2B)-A; (1A:3B)-A: Plantas oriundas das sementes de alto vigor dentro de cada combinação.

(2A:1B)-B; (1A:1B)-B; (1A:2B)-B; (1B:1B)-B: Plantas oriundas das sementes de baixo vigor dentro de cada combinação. (1A:3B)-B1: Planta oriunda da semente de baixo vigor localizada imediatamente ao lado da planta do alto vigor dentro da referida combinação.

(1A:3B)-B2: Planta oriunda da semente de baixo vigor localizada entre duas plantas do baixo vigor dentro da referida combinação. 
produções de matéria seca aos $30 \mathrm{DAE}$, na floração e maturação. $\mathrm{O}$ uso das sementes de alto vigor provocou acréscimos na produção de matéria seca, em torno de $77 \%$ aos 30 DAE e 66\% na floração e maturação. Efeitos do vigor das sementes no desenvolvimento das plantas, também foram constatados em outros trabalhos (SCHUCH et al., 2000; MACHADO, 2002).

A análise individualizada das plantas de soja mostrou que as provenientes das sementes de alto vigor apresentaram maior rendimento de sementes dentro das comunidades (Figura 2). O rendimento foi superior em todos os tratamentos, independentemente da combinação de vigor ao longo da linha de semeadura. O maior rendimento das plantas oriundas das sementes de alto vigor foi devido, principalmente, ao maior número de vagens por planta, já que o número de sementes por vagem e o peso de 1000 sementes, não diferiram entre os tratamentos. O número de sementes por vagem e o peso de 1000 sementes foram em média de 2,0 e 153g, respectivamente. Diferenças no rendimento em função do nível do vigor das sementes, causadas pela variação no número de
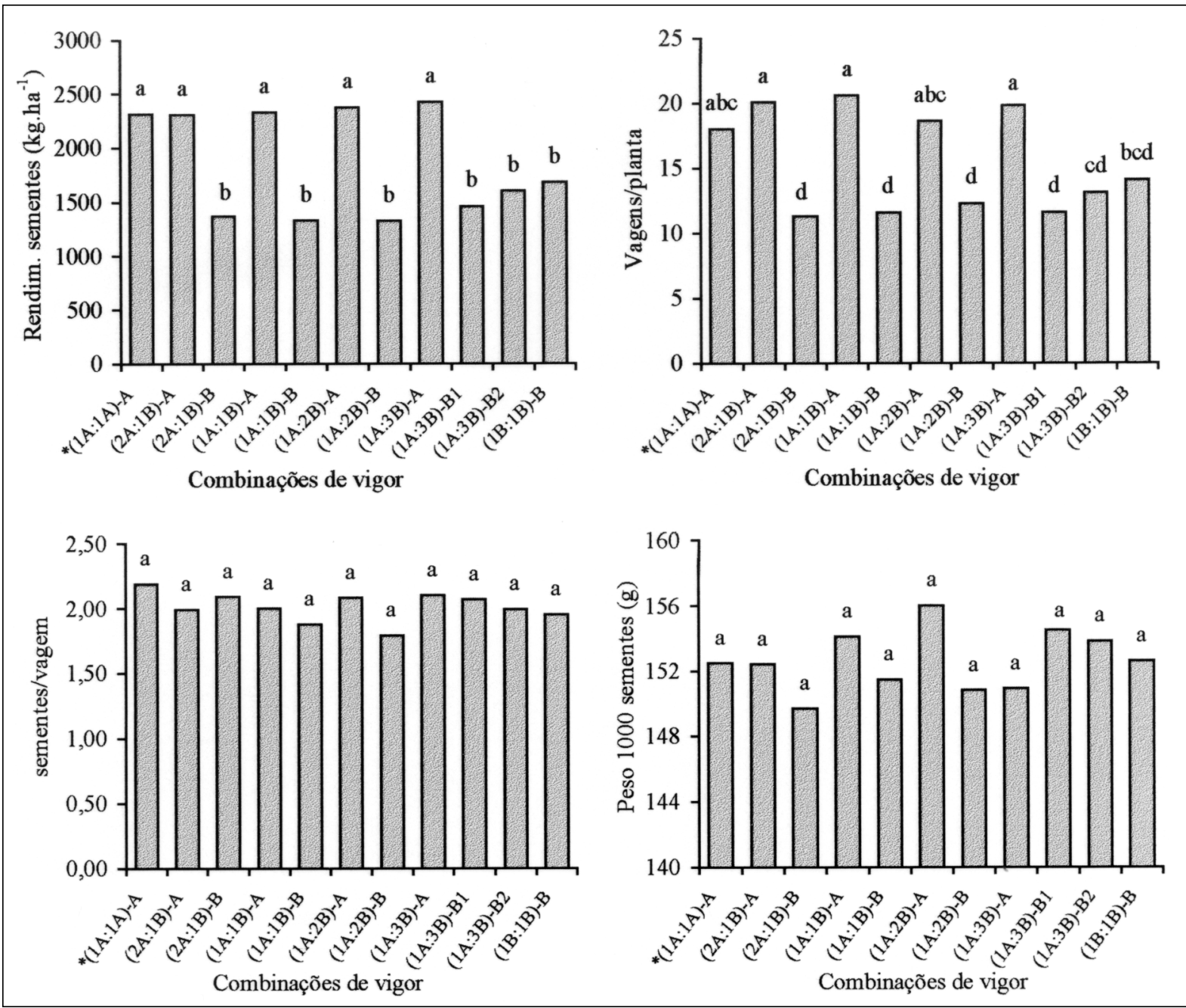

Figura 2 - Rendimento de sementes e componentes de rendimento das plantas individuais dentro das comunidades de plantas de soja, em função de combinações do vigor das sementes. Capão do Leão-RS, 2001/2002.

*(1A:1A)-A; (2A:1B)-A; (1A:1B)-A; (1A:2B)-A; (1A:3B)-A: Plantas oriundas das sementes de alto vigor dentro de cada combinação.

(2A:1B)-B; (1A:1B)-B; (1A:2B)-B; (1B:1B)-B: Plantas oriundas das sementes de baixo vigor dentro de cada combinação. (1A:3B)-B1: Planta oriunda da semente de baixo vigor localizada imediatamente ao lado da planta do alto vigor dentro da referida combinação.

(1A:3B)-B2: Planta oriunda da semente de baixo vigor localizada entre duas plantas do baixo vigor dentro da referida combinação.

Ciência Rural, v.35, n.6, nov-dez, 2005. 
vagens por planta também foram observadas por PINTHUS \& KIMEL (1979).

Os resultados obtidos mostram que as variações no IAF e na produção de matéria seca em função do vigor das sementes (Figura 1) determinaram a produtividade (Figura 2). As plantas originadas das sementes vigorosas apresentaram os maiores valores de IAF e rendimentos de sementes. A partir dos resultados obtidos, pode-se inferir que o rendimento de sementes foi influenciado pelo desempenho das plantas desde os estádios iniciais do crescimento (aos $30 \mathrm{DAE}$ ), e determinado no início da fase reprodutiva em que as plantas provenientes das sementes de alto vigor apresentaram melhor desempenho. Efeitos do vigor das sementes no desenvolvimento das plantas e rendimento, também foram observados por POPINIGIS (1973). O autor constatou que as sementes de alto vigor produziram plantas com maior número de racemos, maior número de vagens, resultando em maior rendimento de sementes.

De acordo com as figuras 1 e 2 , as plantas originadas das sementes vigorosas não exerceram dominância sobre as plantas provenientes das sementes de baixo vigor, adjacentes na linha de semeadura. As plantas de baixo vigor apresentaram IAF, produção de matéria seca e rendimento de sementes semelhante, independentemente da seqüência de nível de vigor ao longo da linha de semeadura. Os valores de rendimento de sementes variaram entre 1322 kg.ha-1 e 1674 kg.ha ${ }^{-1}$, observados nas combinações $1 \mathrm{~A}: 2 \mathrm{~B}$ e $1 \mathrm{~B}: 1 \mathrm{~B}$, respectivamente. Desta forma, não se confirmou a expectativa inicial, de que as plantas originadas das sementes de alto vigor apresentariam um comportamento dominante dentro das comunidades, provocando um efeito restritivo às plantas originadas das sementes de baixo vigor.

Comportamento das comunidades de plantas

O aumento na proporção das plantas originadas das sementes de alto vigor na população elevou linearmente o IAF aos 30 DAE e na floração (Figura 3). A diferença no IAF entre as comunidades constituídas somente por plantas originadas das sementes vigorosas e somente por plantas originadas das sementes de baixo vigor foi de, aproximadamente, $33 \%$ aos 30 DAE e $43 \%$ na floração. Isto sugere que a maior velocidade de emergência das sementes vigorosas e área foliar inicial das plantas (KHAH et al., 1989; SCHUCH, 1999; SCHUCH et al., 2000; MACHADO, 2002; HÖFS, 2003) proporcionam a exploração mais efetiva dos recursos do ambiente. Efeitos do vigor sobre o IAF, também foram constatados por SCHUCH et al. (2000) em aveia preta, em que o uso das sementes de alta qualidade provocou acréscimos de 33\% e 31\%, aos 29 DAE e 113 DAE, respectivamente.

A figura 3 mostra que similarmente ao comportamento do IAF, ocorreu aumento linear na produção de matéria seca com o aumento na proporção das sementes de alto vigor. Na floração, a diferença entre as comunidades constituídas somente por plantas originadas das sementes de alto vigor e somente por sementes de baixo vigor, chegou a $43 \%$. Efeitos do vigor das sementes sobre a produção de matéria seca têm sido relatados na literatura (TEKRONY et al., 1989; SCHUCH et al., 2000). SCHUCH et al. (2000) observaram que as plantas oriundas de sementes vigorosas apresentaram produção de matéria seca $31 \%$ superior as oriundas de sementes de baixo vigor, aos $29 \mathrm{DAE}$.

O aumento na proporção das plantas provenientes das sementes de alto vigor na comunidade proporcionou acréscimo linear no rendimento de sementes (Figura 4). A combinação 1B:1B (somente semente de baixo vigor) apresentou valor de $1674 \mathrm{~kg} \mathrm{ha}^{-1}$, enquanto que a 1A:1A (somente semente de alto vigor), valor de $2318 \mathrm{~kg} \mathrm{ha}^{-1}$, indicando um acréscimo em torno de $38 \%$ no rendimento. Esse comportamento foi determinado pelo aumento no número de vagens por planta, já que o número de sementes por vagem e o peso de 1000 sementes não diferiram entre os tratamentos. Os valores médios do número de sementes por vagem e peso de 1000 sementes foram de 2,0 e 153g, respectivamente (dados não apresentados). Efeitos do vigor das sementes sobre a produção de sementes, também foram constatados por POPINGIS (1973), PINTHUS \& KIMEL (1979), MACHADO (2002), SCHEEREN (2002) e HOFS (2003). Em soja, SCHEEREN (2002) observou que as sementes de alto vigor produziram plantas com maior altura aos 21 dias após a semeadura o que refletiu em maior rendimento final de grãos. POPINIGIS (1973) observou que as plantas de soja provenientes das sementes de alto vigor apresentaram rendimento de sementes, 16\% superior em relação às de baixo vigor.

Segundo os resultados obtidos, os menores rendimentos devidos à redução na proporção das sementes de alto vigor ocorreram porque as plantas originadas das sementes de baixo vigor apresentaram menor rendimento, e não ocorreu um efeito compensatório por parte das plantas originadas das sementes de alto vigor (Figura 2), capaz de proporcionar rendimento de sementes semelhante ao de uma comunidade formada somente por sementes de alto vigor (Figura 4). 

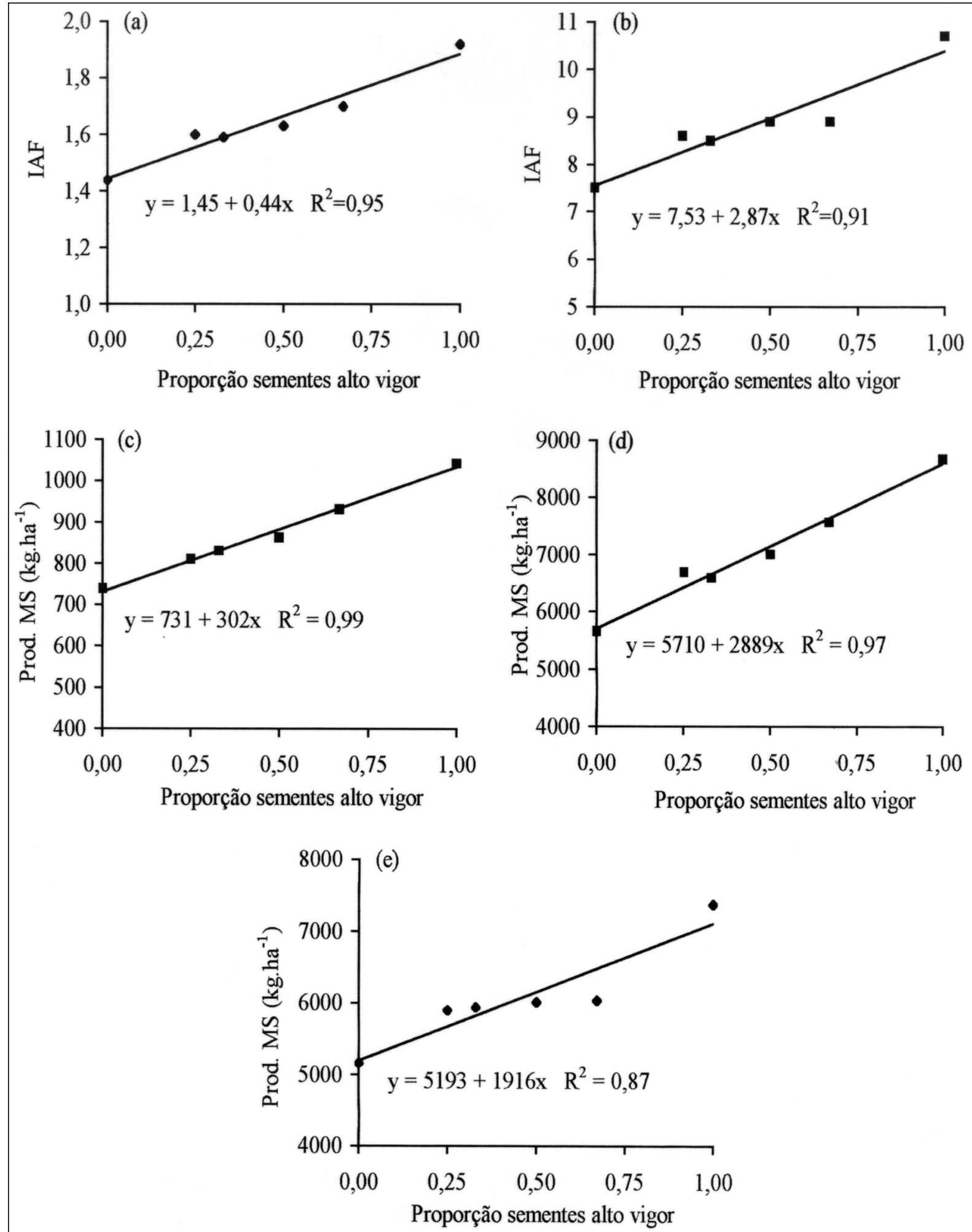

Figura 3 - Índice de área foliar (IAF) aos 30 dias após a emergência (a) e na R2 (b) e produção de matéria seca (MS) aos 30 dias após a emergência (c), na R2 (d) e R7 (e) em soja, em função de diferentes proporções das sementes de alto vigor na população. Capão do Leão-RS, 2001/2002. 


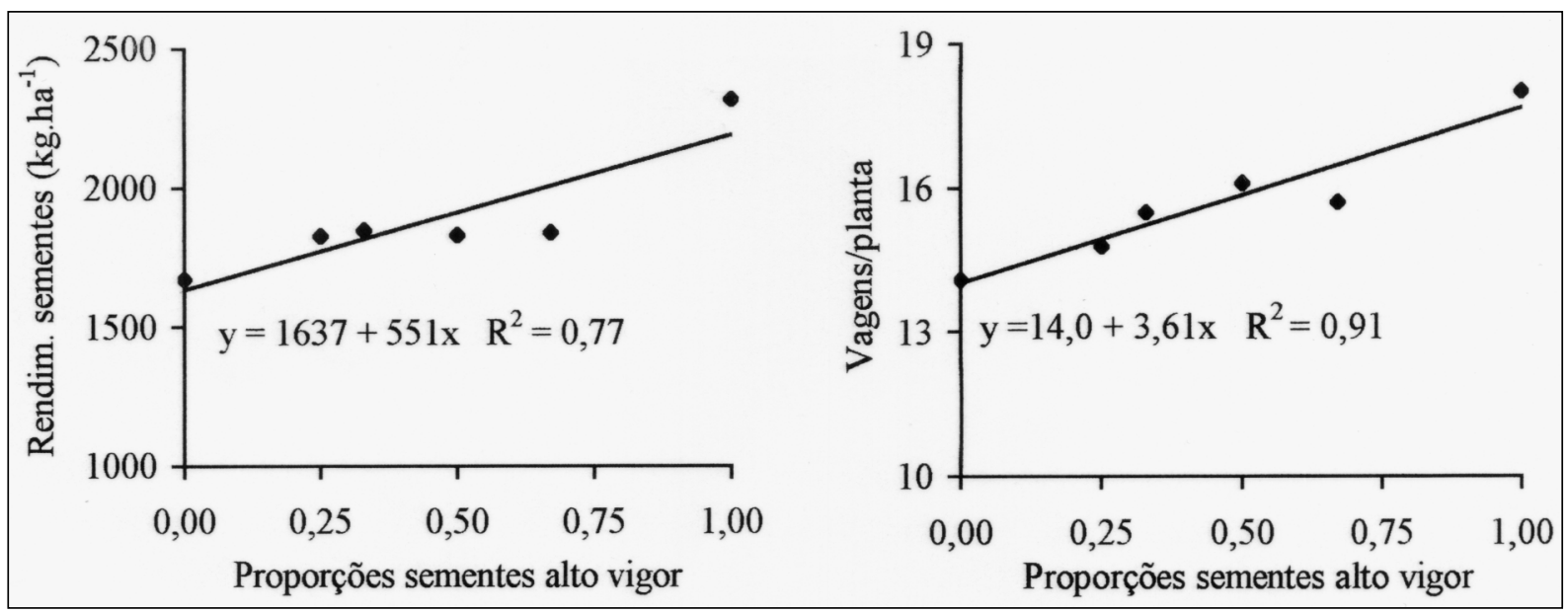

Figura 4 - Rendimento de sementes e número de vagens por planta em soja em função de diferentes proporções das sementes de alto vigor na população. Capão do Leão-RS, 2001/2002.

\section{CONCLUSÕES}

Plantas provenientes das sementes de alto vigor apresentam maior índice de área foliar, produção de matéria seca e rendimento de sementes, mas não apresentam comportamento dominante sobre as plantas de baixo vigor adjacentes na linha de semeadura. Aumentos na proporção das sementes de alto vigor no estabelecimento das comunidades de plantas de soja proporcionam acréscimos no índice de área foliar, na produção de matéria seca e no rendimento de sementes. O uso das sementes de alto vigor proporciona acréscimos superiores a 35\% no rendimento de sementes, em relação ao uso das sementes de baixo vigor.

\section{REFERÊNCIAS}

BLACK, J.N. Competition between plants of different initial seed sizes in swards of subterranean clover (Trifolium subterraneum L.) with particular reference to leaf area and light microclimate. Australian Journal of Agricultural Research, Melbourne, v.9, p.299-318, 1958.

EDJE, O.T.; BURRIS, J.S. Effects of soybean seed vigor on field performance. Agronomy Journal, Madison, v.63, n.4, p.536-538, 1971.

EGLI, D.B. Relatonship of uniformity of soybean seedling emergence to yield. Journal of Seed Technology, East Leasing, v.17, n.1, p.22-28, 1993.

HÖFS, A. Vigor de sementes de arroz e desempenho da cultura. 2003. 44f. Tese (Doutorado em Ciência e Tecnologia de Sementes) - Curso de Pós-graduação em Ciência e Tecnologia de Sementes, Universidade Federal de Pelotas.

KHAH, E.M. et al. Effects of seed ageing on growth and yield of spring wheat at different plant-population densities. Field Crops Research, Bucks, v.20, p.175-190, 1989.
MACHADO, R.F. Desempenho de aveia-branca (Avena sativa L.) em função do vigor de sementes e população de plantas. 2002. 46f. Dissertação (Mestrado em Ciência e Tecnologia de Sementes) - Curso de Pós-graduação em Ciência e Tecnologia de Sementes, Universidade Federal de Pelotas.

MARCOS FILHO, J. Testes de envelhecimento acelerado. In: KRZYZANOWSKI, F.C. et al. (ed). Vigor de sementes: conceitos e testes. Londrina: ABRATES, 1999. Cap.3, p.124 .

MEROTTO JÚNIOR, A. et al. A desuniformidade de emergência reduz o rendimento de grãos de milho. Ciência Rural, Santa Maria, v.29, n.4, p.595-601, 1999.

NAFZIGER, E.D. et al. Response of corn to uneven emergence. Crop Science, Madison, v.31, p.811-815, 1991.

NEDEL, J.L. Effect of nitrogen on $\mathbf{N}$ use, agronomic performance and malting and seed quality of standard height and semi-dwarf isotypes of barley. 1990. 173f. Thesis (PhD in Agronomy) - Washington State University.

PINTHUS, M.J.; KIMEL, U. Speed of germination as a criterion of seed vigor in soybeans. Crop Science, Madison, v.19, p.291-292, 1979

POPINIGIS, F. Effects of the physiological quality of seed on field performance of soybeans (Glycine max (L.) Merrill) as affected by population density. 1973. 87f. Thesis (PhD in Agronomy) - Mississippi State University.

SCHEEREN, B.R. Vigor das sementes de soja e produtividade. 2002. 48f. Tese (Doutorado em Ciência e Tecnologia de Sementes) - Curso de Pós-graduação em Ciência e Tecnologia de Sementes, Universidade Federal de Pelotas.

SCHUCH, L.O.B. Vigor das sementes e aspectos da fisiologia da produção em aveia-preta (Avena strigosa Schreb.). 1999. 127f. Tese (Doutorado em Ciência e 
Tecnologia de Sementes) - Curso de Pós-graduação em Ciência e Tecnologia de Sementes, Universidade Federal de Pelotas.

SCHUCH, L.O.B. et al. Crescimento em laboratório de plântulas de aveia-preta (Avena strigosa Schreb.) em função do vigor das sementes. Revista Brasileira de Sementes, Brasília, v.21, n.1, p.229-234, 1999.
SCHUCH, L.O.B. et al. Vigor de sementes e análise de aveia preta. Scientia Agricola, Piracicaba, v.57, n.2, p.305-312, 2000.

TEKRONY, D.M. et al. Corn seed vigor effect on no-tillage field performance. II. Plant growth and grain yield. Crop Science, Madison, v.29, p.1528-1531, 1989. 